\title{
Relationship between body composition and selected motor components in 17-year-old adolescents residing in the city of Poznań in Poland
}

\author{
Agata Glapa ${ }^{1,3}$, Joanna Grzesiak² Makama Andries Monyeki ${ }^{3}$ \\ ${ }^{1}$ Department of Didactics of Physical Activity, University School of Physical Education, Poznan, Poland; ${ }^{2}$ Department \\ of Neurobiology, University School of Physical Education, Poznan, Poland; ${ }^{3}$ Physical Activity, Sport and Recreation \\ Research Focus Area (PhASReC), North-West University, Potchefstroom, South Africa
}

\section{Summary}

Study aim: The objective of this study was to determine differences in body composition status and levels of selected motor components and assess the relationship between selected motor components and body composition in adolescent girls and boys.

Material and methods: The study participants were 42 girls and 49 boys from a secondary school in the city of Poznan in Poland who were participating in the "Active not only online" project. The percentage of body components was evaluated using a bio-impedance method. The modified Eurofit battery of tests was used to assess selected motor components.

Results: The prevalence of overweight was higher $(12.3 \%)$ in boys than girls $(2.4 \%)$, and girls were more frequently underweight $(16.7 \%)$ than boys $(6.1 \%)$. The results of the study show higher selected motor component levels in girls than in boys when compared to standardized population norms. BMI correlated positively with 20 -m shuttle run $(r=0.45$, $p<0.05)$ in girls and with sit and reach $(\mathrm{r}=0.30, \mathrm{p}<0.05)$ in boys, with 'hand grip' strength both in girls $(\mathrm{r}=0.35, \mathrm{p}<0.05)$ and boys $(\mathrm{r}=0.29$, $\mathrm{p}<0.05)$, and was related to percentage of body fat in girls $(\mathrm{r}=0.33, \mathrm{p}<0.05)$ and boys $(\mathrm{r}=0.42, \mathrm{p}>0.05)$.

Conclusions: The findings showed that sex and body composition are important factors influencing physical fitness in adolescents. We suggest that these factors be considered when designing physical activity interventions.

Key words: Selected motor components - Body mass index status - Fatness - Adolescents

\section{Introduction}

Obesity is a global health problem affecting performance in youth and adults alike. Childhood overweight and obesity have dramatically increased worldwide in recent decades and constitute one of the serious public health challenges of our century [8]. Physical fitness (PF) (mainly cardiorespiratory fitness and muscular strength) during childhood and adolescence is a powerful marker of future health [20], as well as a predictor of morbidity and mortality for cardiovascular disease and its related ailments [19]. Sufficient physical activity (PA) is important for health in adolescents as it has been reported by a number of studies and review papers seeking to identify the correlates of PA in this age group $[21,26]$. According to the World Health Organization [30], children and young people aged 5-17 years should accumulate at least 60 minutes of moderate - to vigorous-intensity physical activity daily and most of their daily PA should be aerobic. Furthermore, vigorous-intensity activities should also be incorporated, including those that strengthen muscles and bones, at least 3 times per week [30]. Unfortunately, studies show that many young people are not meeting the recommendation $[11,18]$.

Although there is overwhelming evidence that PA and obesity are linked, inconsistent findings are reported [29]. One study showed that children and adolescents who are overweight have very low levels of fitness compared with those who are slimmer [20]. In contrast, another study showed that overweight and obese children can perform equally well or even better than children with normal weight in muscular fitness tests [1]. On one hand, overweight is found to be a leading factor associated with inactivity amongst children [16]. On the other hand, underweight is associated with increased mortality of adults and elderly people when compared to normal weight or overweight individuals [10]. As body composition is an 
important component of PF of an individual and provides an indicator of good well-being [25], it should be emphasized as one aspect of a healthy lifestyle among adolescents [26].

Childhood and adolescence are crucial periods of life. Lifestyle and healthy or unhealthy behaviours are established during these years, which may influence adult behaviour and health status. To develop effective PA interventions in youth, influences on, and determinants of, activity levels need to be well understood. Therefore, the objectives of the study design were to determine the body composition status and PF levels and to assess the relationship between body composition and selected motor components for adolescent girls and boys. A study conducted in the Polish context will assist in developing some guidelines for monitoring and improving the level of selected motor components' performance among adolescent students as well as understanding better the impact of body composition on those motor components.

\section{Material and methods}

\section{Study design and participants}

Data for this study were obtained from the "Active not only online" project supported by a Grant Study, Akademickie Centrum Kreatywności (Academic Center of Creativity, no MNiSW/2014/DIR/612/ACK) by the Polish Ministry of Science and Higher Education, that was started in 2015 to conduct a goal setting intervention using PA monitors in youth residing in the city of Poznan in Poland. More information on the setting and study design has been provided elsewhere [3].

The present study included 91 adolescents (42 girls and 49 boys) aged $17.2 \pm 0.27$ years who provided data for body composition, selected motor components, and anthropological fitness variables. The participants were recruited from the same grade level of randomly selected standard urban schools, with a school class as a sample unit. PF and anthropological measures were taken during physical education (PE) classes. Written consent from parents of a minor was also obtained. The study protocol was approved by the Local Bioethics Committee of Karol Marcinkowski University of Medical Sciences in Poznan (decision no. 126/15).

Body mass and height were determined using anthropological instruments. Body height was measured to the nearest 0.5 centimetre $(\mathrm{cm})$ using a stadiometer, and body weight was measured to the nearest 0.1 kilogram $(\mathrm{kg})$ on an electronic scale (Tanita Corporation, Japan). Subsequently, underweight and normal weight as well overweight were classified according to the age- and sex-specific cut-off points for adolescents according to Cole et al. [4, 5]. Using Bodystat 1500, bio-impedance method, the percentage of body fat (BF) and lean body mass (LBM) were measured. All the measurements were taken by trained personnel following the standard operation procedure.

Four PF tests were used in the study: 20-metre shuttle run, Sit and reach, Hand grip and Sit-up test from the standardized European Test of Physical Fitness [9]. The maximal running aerobic fitness was measured with the 20-metre shuttle run. The Sit and reach test measured the flexibility of the lower back and hamstring muscles. The purpose of the Hand grip strength test was to measure grip or forearm muscle strength. The purpose of the Sit-up test was to measure the endurance of the abdominal and hip flexor muscles. All the testing details were presented prior to the test by trained personnel who took the measures.

\section{Statistical analysis}

Descriptive characteristics (means, standard deviations and frequencies) were calculated for body composition and selected motor components for the total group and separately for boys and girls (compared to age-related national population norms) [6]. Comparisons for sex and BMI categories were performed using the independent $t$-test and Pearson's $\chi^{2}$ test. The Pearson correlation coefficient $(r)$ was calculated to determine the relationship between selected motor components and body composition among adolescents. The level of significance was set at $\mathrm{p}<0.05$. Statistical analysis was carried out using the Statistica 13.0 software.

\section{Results}

The study sample consisted of 91 adolescents $(17.2 \pm 0.27$ years) from a secondary school. The results show a significant mean age difference $(\mathrm{p}<0.05)$ between girls $(17.3 \pm 0.27$ years $)$ and boys $(17.2 \pm 0.28$ years $)$. For all five anthropometric measures (height, body mass, BMI, \%BF, LBM), we found significant differences between girls and boys. Out of 91 participants (46.2\% girls and $53.8 \%$ of boys), the prevalence of normal BMI was $81.3 \%$, of underweight was $11.0 \%$, and of overweight was $7.7 \%$. Furthermore, analysis by sex showed that a higher percentage of boys (12.3\%) were classified as 'overweight' in comparison to girls $(2.4 \%)$. The results also showed that more girls were classified as 'underweight' (16.7\%) in comparison to boys (6.1\%). In general, the BMI results obtained by boys were within the $50-75^{\text {th }}$ percentiles and in girls they were within the $25-50^{\text {th }}$ percentiles. For height and weight, for both sexes, the levels of the $50-75^{\text {th }}$ percentiles were obtained. The characteristics of the study sample are presented in Table 1.

Girls $(25.0 \pm 7.72 \mathrm{~cm})$ scored significantly better results in the sit and reach test than boys $(19.1 \pm 9.74 \mathrm{~cm})$. Looking at the national age-related norms, girls obtained 
Table 1. Number of participants, mean and standard deviation of age and anthropometric measures among adolescents by sex

\begin{tabular}{|c|c|c|c|c|c|}
\hline \multirow{2}{*}{ Variables } & Total $(\mathrm{N}=91)$ & Girls $(n=42)$ & Boys $(n=49)$ & \multirow{2}{*}{$p$-value } & \multirow{2}{*}{ Cohen's $d s$} \\
\hline & Mean \pm SD & Mean \pm SD & Mean \pm SD & & \\
\hline Age [years] & $17.2 \pm 0.27$ & $17.3 \pm 0.24$ & $17.2 \pm 0.28$ & 0.025 & 0.50 \\
\hline Height $[\mathrm{cm}]$ & $174.4 \pm 9.80$ & $166.2 \pm 6.1$ & $181.4 \pm 6.30$ & $<0.001$ & 2.45 \\
\hline Body mass [kg] & $65.1 \pm 11.2$ & $57.5 \pm 7.93$ & $71.9 \pm 11.07$ & $<0.001$ & 1.50 \\
\hline $\mathrm{BMI}\left[\mathrm{kg} / \mathrm{m}^{2}\right]$ & $21.2 \pm 2.67$ & $20.5 \pm 2.31$ & $21.7 \pm 2.87$ & 0.043 & 0.44 \\
\hline $\mathrm{BF}[\%]$ & $22.6 \pm 8.05$ & $28.7 \pm 5.90$ & $17.3 \pm 5.58$ & $<0.001$ & 1.98 \\
\hline LBM $[\%]$ & $73.5 \pm 17.48$ & $65.8 \pm 17.07$ & $80.1 \pm 15.10$ & $<0.001$ & 0.89 \\
\hline \multicolumn{6}{|l|}{ BMI categories } \\
\hline Normal & $74(81.3 \%)$ & $34(80.9 \%)$ & $40(81.6 \%)$ & \multirow{3}{*}{ ns } & \\
\hline Underweight & $10(11.0 \%)$ & $7(16.7 \%)$ & $3(6.1 \%)$ & & \\
\hline Overweight & $7(7.7 \%)$ & $1(2.4 \%)$ & $6(12.3 \%)$ & & \\
\hline
\end{tabular}

$\mathrm{N} / \mathrm{n}$ - number of participants, SD - standard deviation, BMI - Body mass index, BF - the percentage of body fat, LBM - the percentage of lean body mass and ns - not significant; $p$-values were derived from the Independent $t$-test for numerical and Person's $X^{2}$ for categorical variables.

results above the $97^{\text {th }}$ percentile, while boys obtained results between the $90^{\text {th }}$ and $97^{\text {th }}$ percentiles. Significant differences were observed regarding other selected motor variables with boys having greater values for the sit-up test $(26.5 \pm 4.41 \mathrm{n} / \mathrm{sec})$ and hand grip test $(46.1 \pm 10.33 \mathrm{~kg})$ than girls $(24.2 \pm 3.77 \mathrm{n} / \mathrm{sec}, 32.7 \pm 5.28 \mathrm{~kg}$, respectively $)$ $(\mathrm{p}<0.05)$. No significant difference between girls and boys was observed for the 20-m shuttle run test. However, in reference to the population-wide norms for sits-ups, hand grip and 20-m shuttle run, girls scored higher results on the percentiles charts than boys. The descriptive data for selected motor components of adolescents are provided in Table 2.

The correlation between body composition and PF items among girls and boys shows that BMI was positively related to \%BF both in girls $(r=0.33, p<0.05)$ and in boys $(r=0.42, p>0.05)$. BMI was also positively related to percentage body fat in girls $(r=0.33, p<0.05)$ and in boys $(r=0.42, p<0.05)$. A significant positive relationship between BMI and sit and reach $(r=0.30, p<0.05)$, and between BMI and handgrip $(r=0.29, p<0.05)$ in the group of boys were found. Generally, the correlation coefficients $(r)$ of the relationship between body composition and PF were moderate (Table 3 ).

\section{Discussion}

This present study provides data on the body composition status, selected motor components and the relationship between those variables for adolescent girls and boys. In our study, the majority of adolescents were classified in the 'normal' BMI category. Generally, boys showed a higher prevalence of overweight than girls, while girls showed a higher prevalence of underweight than boys. One possible explanation for our results might be that adolescent girls are more concerned about their body weight and image than boys. Furthermore, they are in a period of dynamic growth and of rapid biological development and maturation. It is also possible that cultural pressure might be a central factor influencing 'body shape' in modern adolescent girls worldwide. The study of Mikolajczyk and

Table 2. Descriptive statistics (mean, standard deviation) for selected motor fitness items among adolescents

\begin{tabular}{|c|c|c|c|c|c|}
\hline \multirow{2}{*}{ Variables } & Total $(\mathrm{N}=91)$ & Girls $(n=42)$ & Boys $(n=49)$ & \multirow{2}{*}{$p$-value } & \multirow{2}{*}{ Cohen's $d s$} \\
\hline & Mean \pm SD & Mean \pm SD & Mean \pm SD & & \\
\hline Sit and reach $[\mathrm{cm}]$ & $21.8 \pm 9.31$ & $25.0 \pm 7.72$ & $19.1 \pm 9.74$ & 0.002 & 0.68 \\
\hline Sit-ups [n/sec.] & $25.4 \pm 4.27$ & $24.2 \pm 3.77$ & $26.5 \pm 4.41$ & 0.009 & 0.57 \\
\hline 20-MST [min] & $6.6 \pm 2.27$ & $6.6 \pm 2.32$ & $6.7 \pm 2.25$ & ns & 0.03 \\
\hline Hand grip $[\mathrm{kg}]$ & $39.9 \pm 10.71$ & $32.7 \pm 5.28$ & $46.1 \pm 10.33$ & $<0.001$ & 1.64 \\
\hline
\end{tabular}

$\mathrm{SD}$ - standard deviation, ns - not significant, $\mathrm{cm}$ - centimetres, $\mathrm{n} / \mathrm{sec}$. - number of sit ups in 30 seconds, min - minutes, kg - kilograms, MST 20 -m shuttle run. $P$-values were divided from the Independent $t$-test for numerical variables. 
Table 3. Correlation matrix between body composition and selected motor fitness items among secondary school girls and boys

\begin{tabular}{|c|c|c|c|c|c|c|c|}
\hline Variables & $\mathrm{BF}$ & LBM & BMI & Sit and reach & Sit-ups & 20-MST & Hand grip \\
\hline \multicolumn{8}{|l|}{ Girls } \\
\hline \multicolumn{8}{|l|}{$\mathrm{BF}$} \\
\hline LBM & -0.25 & & & & & & \\
\hline BMI & 0.33 & 0.00 & & & & & \\
\hline Sit and reach & -0.22 & 0.01 & 0.03 & & & & \\
\hline Sit-ups & -0.04 & -0.26 & -0.12 & 0.07 & & & \\
\hline 20-MST & 0.24 & -0.02 & 0.45 & 0.28 & -0.27 & & \\
\hline \multirow[t]{2}{*}{ Hand grip } & -0.23 & 0.12 & 0.35 & 0.00 & 0.09 & 0.11 & \\
\hline & $\mathrm{BF}$ & LBM & BMI & Sit and reach & Sit-ups & 20-MST & Hand grip \\
\hline \multicolumn{8}{|l|}{ Boys } \\
\hline \multicolumn{8}{|l|}{$\mathrm{BF}$} \\
\hline LBM & -0.45 & & & & & & \\
\hline BMI & 0.42 & -0.10 & & & & & \\
\hline Sit and reach & -0.10 & 0.01 & 0.30 & & & & \\
\hline Sit-ups & 0.04 & -0.27 & -0.00 & 0.25 & & & \\
\hline 20-MST & 0.02 & 0.17 & 0.05 & -0.12 & 0.04 & & \\
\hline Hand grip & 0.22 & -0.04 & 0.29 & 0.03 & 0.04 & -0.13 & \\
\hline
\end{tabular}

BMI - Body mass index, BF - the percentage of body fat and LBM - the percentage of lean body mass, 20-MST - 20-m shuttle run. Significant correlations are indicated in bold.

Richter [17] among adolescents in Germany showed that $9.5 \%$ of boys and $5.4 \%$ of girls were classified as overweight, while the prevalence of underweight was $12.6 \%$ among boys and $19.1 \%$ among girls. In a Polish study by Kantanista and Osinski [15], underweight was reported to be $7 \%$ and $11.6 \%$ respectively, in adolescent boys and girls. Hoffmann et al. [13], in their research on the young population of the urban area in the Poznan Region consisting of 116 students aged 15-17 years, 61 males $(52.7 \%)$ and 55 females $(47.3 \%)$, indicated that there was a higher percentage of participants with excessive body mass, among whom at least half were obese, and boys were much more obese than girls. In our study, boys had a greater $\% \mathrm{LBM}$ than girls, while girls had a higher $\% \mathrm{BF}$ compared with boys, and these observations suggest that girls are more at risk of being overweight in the future. At the same time, girls had a lower BMI than boys. Similar findings have been reported in previous studies, where boys had greater muscle mass and a lower \%BF than girls across age groups [21]. The results obtained by Przewęda [23] in nationwide studies conducted among school youth confirm that in contemporary Polish youth there are increasing rates of overweight and even obesity, which may indicate an obesity epidemic in the future. Przewęda [23] also stated that every decade we observe somatically larger and physically weaker adolescents, which is a serious danger to the health of young Poles.
On one hand, girls showed better performance than boys in the sit and reach fitness item, which is similar to the previous studies [27]. On the other hand, boys performed better than girls in explosive strength and the endurance of muscles, which is also in line with other studies [18]. However, according to the national related norms, the results showed higher scores in selected motor components for girls than boys (sit and reach test, sit-up test, 20-m shuttle run test and hand grip test). Our results are in contrast to the results of Dobosz et al. [7], where boys showed better physical fitness levels than girls, except for the flamingo balance, sit and reach, and stand and reach test, in which girls performed slightly better. A possible explanation of better scores obtained by girls in our study could by the high quality of physical education teaching in the school where the study was done. In that school students tend not to intentionally skip classes and the surveyed girls were already very active and took care of their health and appearance.

The present study also examined the correlation between body composition and selected motor items among adolescent girls and boys. BMI was related to $\% \mathrm{BF}$ in girls and in boys, which is comparable to the result of Pietrobelli et al. [22]. We also observed a significant and positive relationship between BMI and 20-m shuttle run in the group of girls and a positive relationship between BMI and hand grip. Also, a significant positive relationship between BMI and sit and reach, as well as between BMI and hand grip, in the group 
of boys was found. The correlations were in general moderate. Partly, similar results have been reported by Hands et al. [11], where BMI was weakly and negatively correlated with muscle endurance, and positively correlated with aerobic fitness and muscle strength, for both males and females. Overall, a possible explanation of those correlations could be the nature of the physical education's core curriculum, which may reflect the type and variety of activities typically undertaken by adolescents in classes conducted separately for girls and boys. Similar trends were observed in an earlier study on Polish adolescents [3], where it was also found that for the long-term effects of school-based physical activity young people need to develop a sense of coherence and self-responsibility. Also, Kantanista et al. [14] found a correlation between effectiveness of school-based interventions increasing the volume of activities (including in out-of-school leisure time) and biological and psychological characteristics of Polish adolescents. Generally, it seems that during PE classes boys undertake more musclestrengthening activities while girls undertake more fitness activities (aerobic activities).

Some strengths and limitations are worth noting. Firstly, the sample consisted of all students in the same age category from the same school, which might be considered a strength. Secondly, due to the relatively small sample size drawn only from adolescents of the city of Poznan in the present study, the children's exercise performance and its impact on their body composition could not be verified more comprehensively. Thirdly, maturation may have affected the results, but, unfortunately, data on maturation were not collected within the present study. In general, the relationship between selected motor components and body composition in adolescents still requires further research, which should cover a larger sample size and should take into consideration the maturation period.

\section{Conclusions}

In conclusion, the majority of 17-year-old adolescent females and males are classified as having a 'normal' BMI. Generally, boys showed a higher prevalence of overweight than girls, while girls showed a higher prevalence of underweight than boys. Girls showed better performance than boys in the sit and reach fitness item. Boys performed better than girls in explosive strength and the endurance of muscle performance. However, according to the population-wide physical fitness norms (percentiles), girls performed better in all selected motor components. Moderate correlations between BMI and 20-m shuttle run in girls and sit and reach in boys, with 'hand grip' strength both in girls and boys, and with percentage of body fat in girls and boys were found.

Future PA interventions aimed at facilitating changes in PA level should take into consideration these factors, particularly in underweight and overweight adolescents. The differences between girls and boys in perceived body composition and measured selected motor components highlight the need for a comprehensive PA programme for secondary school students.

Conflict of interest: Authors state no conflict of interest.

\section{References}

1. Artero E.G., Espana-Romero V., Ortega F.B., JimenezPavon D., Ruiz J.R., Vicente-Rodriguez G., Bueno M., Marcos A., Gomez-Martinez S., Urzanqui A., Gonzalez-Gross M., Moreno L.A., Gutierrez A., Castillo M.J. (2010) Health-related fitness in adolescents: underweight, and not only overweight, as an influencing factor. The AVENA study. Scand. J. Med. Sci. Sports, 20: 418-27. DOI: 10.1111/j.1600-0838.2009.00959.x.

2. Bronikowski M. (2010) Is sense of coherence needed to keep youth physically active? Med. Sport, 63(4): 653-483.

3. Bronikowski M., Bronikowska M., Glapa A. (2016) Do they need goals or support? A Report from a goalsetting intervention using physical activity monitors in youth. Int. J. Environ. Res. Public Health,13: 914. DOI: 10.3390/ijerph13090914.

4. Cole T.J., Bellizzi M.C., Flegal K.M., Dietz W.H. (2000) Establishing a standard definition for childoverweight and obesity worldwide: international survey. $B M J, 330$ : 1240-1244. DOI: 10.1136/bmj.320.7244.1240.

5. Cole T.J., Flegal K.M., Nicholls D., Jackson A.A. (2007) Body mass index cut offs to define thinness in children and adolescents: international survey. BMJ, 335: 194. DOI: 10.1136/bmj.39238.399444.55.

6. Dobosz J. (2012). Physical fitness condition of children and adolescents at school age. Percentiles. Warszawa.

7. Dobosz J., Mayorga-Vega D., Viciana J. (2015). Percentile Values of Physical Fitness Levels among Polish Children Aged 7 to 19 Years-a Population-Based Study. Cent. Eur. J. Public Health, 23(4): 340.

8. Ebbeling C.B., Pawlak D.B., Ludwig D.S. (2002) Childhood obesity: public-health crisis, common sense cure. Lancet., 360: 473-482. DOI: 10.1016/S0140-6736(02)09678-2.

9. Eurofit (1988) European test of physical fitness. Rome: Council of European Committee for Development of Sport.

10. Flegal K.M., Graubard B.I., Williamson D.F., Gail M.H. (2005) Excess deaths associated with underweight, overweight, and obesity. JAMA, 293: 1861-1867. DOI: 10.1001/jama.293.15.1861.

11. Hands B., Larkin D., Parker H., Straker L., Perry M. (2009) The relationship among physical activity, motor competence and health-related fitness in 14-year-old 
adolescents. Scand. J. Med. Sci. Sports, 19: 655-663. DOI: 10.1111/j.1600-0838.2008.00847.x.

12. Harding S.K., Page A.S., Falconer C., Cooper A.R. (2015) Longitudinal changes in sedentary time and physical activity during adolescence. Int. J. Behav. Nutr. Phys. Act., 12(1): 44. DOI 10.1186/s12966-015-0204-6.

13. Hoffmann K., Bryl W., Marcinkowski J.T., Strazynska A., Pupek-Musialik D. (2011) Estimation of physical activity and prevalence of excessive body mass in rural and urban Polish adolescents. Ann. Agric. Environ. Med., 18: 398-403.

14. Kantanista A., Bronikowski M., Laudańska-Krzemińska I., Osiński W. (2014) Effects of pedometer-based walking intervention on phychological and biological variables in adolescent girsl: does achieving goals make a difference? Med. Sport, 67(2): 261-272.

15. Kantanista A., Osinski W. (2014) Physical activity of Poles - critical analysis of research 2010-2014. Ann. Agric. Environ. Med., 21: 839-843.

16. Metacalf B.S., Hosking J., Jeffery A.N., Voss L.D., Henley W., Wilkin T.J. (2011) Fatness leads to inactivity, but inactivity does not lead to fatness: a longitudinal study in children (EarlyBird 45). Arch. Dis. Child., 96: 942-947. DOI: 10.1136/adc.2009.175927.

17. Mikolajczyk R.T., Richter M. (2008) Associations of behavioural, psychosocial and socioeconomic factors with over - and underweight among German adolescents. Int. J. Public Health, 53(4): 214-220. DOI 10.1007/s00038008-7123-0.

18. Monyeki M.A., Neetens R., Moss S.J., Twisk J. (2012) The relationship between body composition and physical fitness in 14 year old adolescents residing within the Tlokwe local municipality, South Africa: the PAHL study. BMC Public Health, 12: 374. DOI: 10.1186/1471-245812-374.

19. Myers J., Prakash M., Froelicher V., Do D., Partington S., Atwood J.E. (2002) Exercise Capacity and Mortality among Men Referred for Exercise Testing. N. Engl. J. Med., 346: 793-801. DOI: 10.1056/NEJMoa011858.

20. Ortega F.B., Ruiz J.R., Castillo M.J., Sjöström M. (2008) Physical fitness in childhood and adolescence: a powerful marker of health. Int. J. Obes., 32: 1-11. DOI: 10.1038/ sj.ijo.0803774.

21. Pangrazi R.P., Corbin C.B. (1990) Age as a Factor Relating to Physical Fitness Test Performance. Res. Q. Exerc. Sport, 61(4): 410-414.

22. Pietrobelli A., Faith M.S., Allison D.B., Gallagher D., Chiumello G., Heymsfield S.B. (1998) Body mass index as a measure of adiposity among children and adolescents: A validation study. J. Pediatr., 132: 204-210. DOI: 10.1016/S0022-3476(98)70433-0.

23. Przewęda R. (2009). Changes in the physical fitness condition of Polish youth in the last decades. Studia Ecologiae et Bioethicae, 7(1): 57-71.
24. Sallis J.F., Prochaska J.J., Taylor W.C. (2000) A review of correlates of physical activity of children and adolescents. Med. Sci. Sports Exerc., 32: 963-975. DOI: 10.1097/00005768-200005000-00014.

25. Saris W.H.M., Rissanen A., Blair S.N., Van Baak M.A., Eaton S.B., Davies P.S.W., Di Pietro L., Fogelholm M., Rissanen A., Schoeller D., Swinburn B., Tremblay A., Westerterp K.R., Wyatt H. (2003) How much physical activity is enough to prevent unhealthy weight gain? Outcome of the IASO 1st Stock Conference and consensus statement. Obes. Rev., 4: 101-114. DOI: 10.1046/j.1467789X.2003.00101.x.

26. Shang X., Liu A., Li Y., Hu X., Du L., Ma J., Xu G., Li Y., Guo H., Ma G. (2010) The association of weight status with physical fitness among chinese children. Int. J. Pediatr., 515-414. DOI: 10.1155/2010/515414.

27. Thompson A., Baxter-Jones A.D., Mirwald R.L., Bailey D.A. (2003) Comparison of physical activity in male and female children: does maturation matter? Med. Sci. Sports Exerc., 35: 1684-1690. DOI: 10.1249/01. MSS.0000089244.44914.1F.

28. Van Der Horst K., Paw M.J., Twisk J.W., Van Mechelen W. (2007) A brief review on correlates of physical activity and sedentariness in youth. Med. Sci. Sports Exerc., 39: 1241-1250. DOI: 10.1249/mss.0b013e318059bf35.

29. Wareham N.J., Van Sluijs E.M.F., Ekelund U. (2005) Physical activity and obesity prevention: a review of the current evidence. Proc. Nutr. Soc., 64: 229-247. DOI: 10.1079/PNS2005423.

30. World Health Organization. (2015) Global Recommendation on Physical Activity for Health. Available online: http://www.who.int/dietphysicalactivity/publications/pa/ en/ (accessed on 25 April 2016).

\section{Received 21.09.2017 \\ Accepted 28.03.2018}

(C) University of Physical Education, Warsaw, Poland

\section{Acknowledgments}

The cooperation of the IX Secondary School in Poznan and their school authorities, PE teachers, children, parents and students from the University School of Physical Education in Poznan is greatly appreciated. Special thanks for Professor Melainie Cameron for proofreading the paper.

\section{Financial Support}

This research was supported by a Grant Study Akademickie Centrum Kreatywności (Academic Center of Creativity, no MNiSW/2014/DIR/612/ACK) by the Polish Ministry of Science and Higher Education. 